OPEN ACCESS

Edited by:

Lei Wu,

Zhejiang University, China

Reviewed by:

Zhong-Hai Li,

University of Chinese Academy of

Sciences, China

Jie Liao,

Sun Yat-sen University, Zhuhai

Campus, China

*Correspondence:

Lin Chen

sinica.lin@gmail.com

Specialty section:

This article was submitted to

Solid Earth Geophysics,

a section of the journal

Frontiers in Earth Science

Received: 09 August 2021 Accepted: 03 September 2021 Published: 15 September 2021

Citation:

Chen L (2021) The Role of Lower Crustal Rheology in Lithospheric

Delamination During Orogeny.

Front. Earth Sci. 9:755519.

doi: 10.3389/feart.2021.755519

\section{The Role of Lower Crustal Rheology in Lithospheric Delamination During Orogeny}

\section{Lin Chen*}

State Key Laboratory of Lithospheric Evolution, Institute of Geology and Geophysics, Chinese Academy of Sciences, Beijing, China

The continental lower crust is an important composition- and strength-jump layer in the lithosphere. Laboratory studies show its strength varies greatly due to a wide variety of composition. How the lower crust rheology influences the collisional orogeny remains poorly understood. Here I investigate the role of the lower crust rheology in the evolution of an orogen subject to horizontal shortening using 2D numerical models. A range of lower crustal flow laws from laboratory studies are tested to examine their effects on the styles of the accommodation of convergence. Three distinct styles are observed: 1) downwelling and subsequent delamination of orogen lithosphere mantle as a coherent slab; 2) localized thickening of orogen lithosphere; and 3) underthrusting of peripheral strong lithospheres below the orogen. Delamination occurs only if the orogen lower crust rheology is represented by the weak end-member of flow laws. The delamination is followed by partial melting of the lower crust and punctuated surface uplift confined to the orogen central region. For a moderately or extremely strong orogen lower crust, topography highs only develop on both sides of the orogen. In the Tibetan plateau, the crust has been doubly thickened but the underlying mantle lithosphere is highly heterogeneous. I suggest that the subvertical high-velocity mantle structures, as observed in southern and western Tibet, may exemplify localized delamination of the mantle lithosphere due to rheological weakening of the Tibetan lower crust.

Keywords: lithosphere, delamination (A), Tibetan plateau (TP), topography (Earth), rheology

\section{INTRODUCTION}

It is widely thought that the lithosphere mantle thickens in concert with the crust during continental collision (England and Houseman, 1986). Owing to its positive buoyancy, thickening of the continental crust by horizontal shortening often gives rise to orogens or orogenic plateaus. However, increasing evidence shows the thick orogenic crust is not necessarily underlain by an equivalently thick lithosphere mantle. For example, seismological studies indicate that the India-Asia collision results in the double normal thickness crust of Tibet (e.g., Hirn et al., 1984), but the Tibetan lithosphere mantle does not thicken proportionally. In the central Tibetan plateau, the lithosphere mantle is thinner than the normal continental lithosphere or even missing (Owens and Zandt, 1997; Nabelek et al., 2009). Similar phenomena are also observed in the Altiplano plateau. Seismic studies show low velocities and high attenuation in the shallow mantle in the Central Andes, implying the absence of the lithospheric mantle beneath much of the orogen, even though the crust thickness ranges from 50 to $75 \mathrm{~km}$ (Yuan et al., 2000; Beck and Zandt, 2002; Schurr et al., 2006). The 


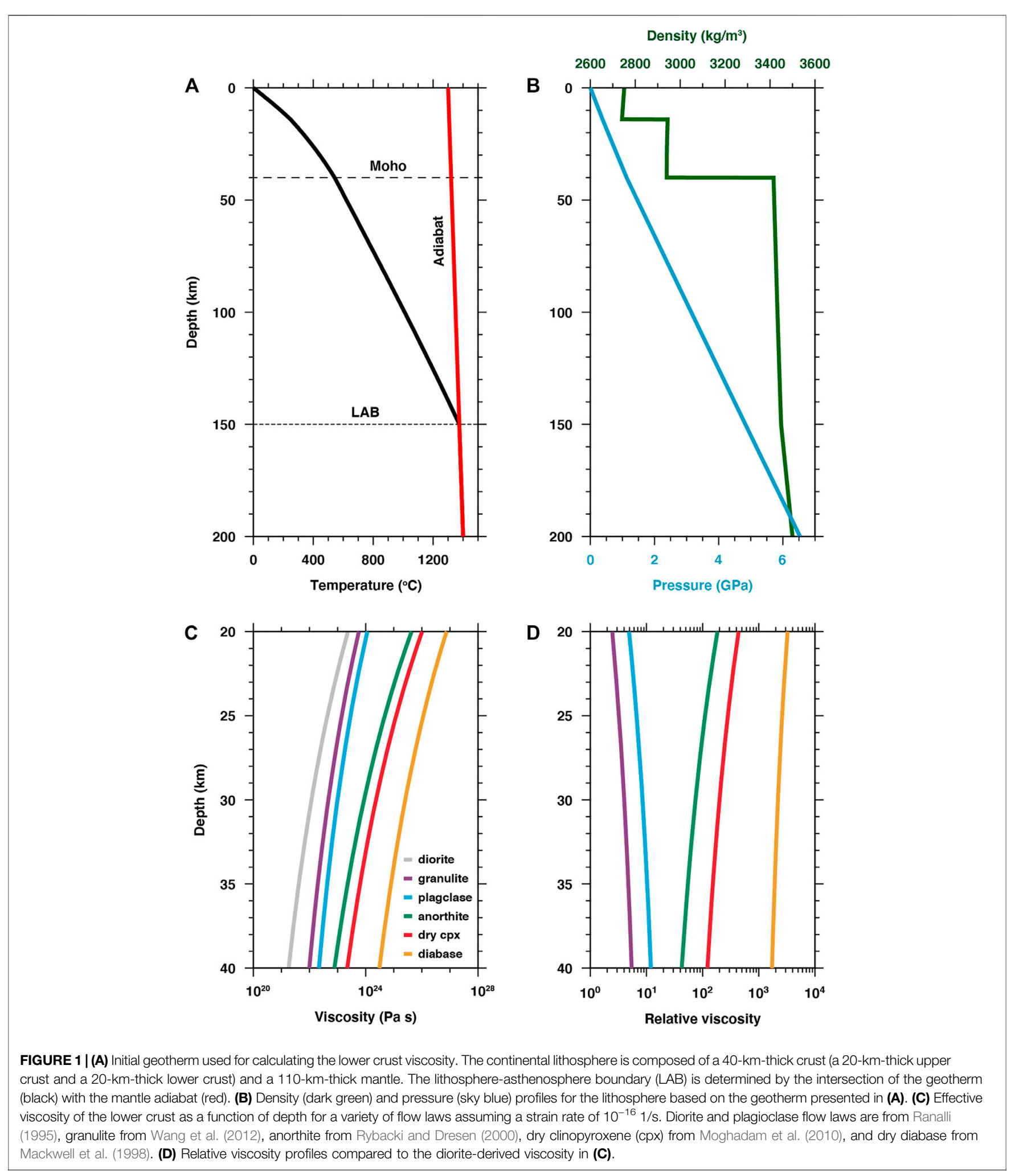

discrepancy between the crustal and lithospheric thicknesses under orogens raise an important question: What is the fate of the mantle portion of the lithosphere during orogeny?
Several hypotheses have been proposed to explain the lithospheric mantle loss during orogeny (e.g., Gogus and Pysklywec, 2008). They can be categorized into two types. One 
is convective removal through gravitational instability (e.g., Houseman et al., 1981; Conrad and Molnar, 1999; Gorczyk et al., 2012). This hypothesis requires no pre-existing structural weakness, but requires that the lithosphere mantle is denser than the underlying asthenosphere or a thickened region (sufficient perturbation with a suitable wavelength) in the lithosphere (Schott and Schmeling, 1998; Elkins-Tanton, 2007). Recent studies indicate that the continental lithosphere is largely neutrally buoyant (e.g., Lee et al., 2011), which deviates from the requirement. The other is commonly called delamination in literature, which originally indicates that the cold lithosphere mantle peels away as a coherent slice from the crust via an elongated conduit connecting the base of the crust with the asthenosphere (Bird, 1979). The delaminated cold mantle is replaced by hot asthenosphere and would cause surface uplift, elevated heat flow, reduced seismic velocities, and magmatism (Bird, 1979; Kay and Kay, 1993; Ducea and Saleeby, 1998). This mechanism requires a pre-existing weakness to initiate delamination, which is not necessarily met during collisional orogeny. Previous modeling studies on lithospheric mantle removal have highlighted the importance of viscous rheology of the mantle lithosphere (Buck and Toksoz, 1983; Conrad and Molnar, 1997; Houseman and Molnar, 1997), thermal diffusion (Conrad and Molnar, 1999), mechanical thickening (Molnar et al., 1998; Conrad, 2000), compositional density variations of the lower crust (Jull and Kelemen, 2001; Elkins-Tanton, 2005; Krystopowicz and Currie, 2013), Moho temperature (Morency and Doin, 2004), lower crust radioactive heating (Pysklywec and Beaumont, 2004), and prescribed weak zones or lithosphere perturbation root (Schott and Schmeling, 1998; Gogus and Pysklywec, 2008; Bajolet et al., 2012) in the lithosphere mantle removal. However, few studies paid attention to the lower crust rheology (e.g., Meissner and Mooney, 1998).

Laboratory results show that the continental lower crust rheology differs strongly as a function of composition, temperature, stress, and fluids (Burgmann and Dresen, 2008). There is great variety in composition and chemical and physical properties of the continental lower crust (Lee, 2014; Hacker et al., 2015). This results in large uncertainty about the lower crust rheology. Figure 1 shows the comparison among viscosities calculated from six laboratory-derived lower crust flow laws using the same geotherm and pressure curves. They encompass a wide variation of the lower crust minerals or rocks, ranging from felsic diorite to mafic diabase. It is evident that the diabase viscosity is at least three orders of magnitude greater than that of diorite at the same lower crust condition. Thus, an unresolved problem is how the uncertainty in the lower crust rheology influences crustal deformation and mantle dynamics during collisional orogeny.

In this study, I use 2D high-resolution thermal-mechanical to examine the role of the lower crust rheology in the deformation of the continental lithosphere subject to horizontal shortening. I systematically investigate variations in the lower crust rheology derived from laboratory studies to understand the conditions required for lithospheric mantle removal and its surface expressions. In contrast to some previous studies, I do not impose initial lithosphere thickness perturbation or local weaknesses. Instead, lithospheric thickening and/or delamination develop self-consistently during model evolution. This study focuses on the variations in the laboratory-derived rheologies of the lower crust and fate of the lithosphere mantle during continental compression.

\section{NUMERICAL MODELLING OF COUPLED LITHOSPHERIC DEFORMATION AND TOPOGRAPHY EVOLUTION}

\section{Numerical Method}

I use I2VIS, which combines a conservative finite difference method and a marker-in-cell technique, to solve the governing equations of momentum, mass, and energy in incompressible flow (Gerya and Yuen, 2003). Rock properties are advected on the moving Lagrangian markers. A composite rheological model described below is employed to account for plastic deformation and creeping flow of rocks. The method considers the effects of adiabatic, shear, latent and radioactive heating. A full description of the method, including the implementation of partial melting, can be found in the textbook by Gerya (2010). All the related parameters used in the study follow the Table 17.2 in Gerya (2010).

\section{Model Setup}

Figure 2 shows the initial configuration and thermomechanical state of our experiments. The whole computational domain is $4,000 \mathrm{~km}$ wide and $820 \mathrm{~km}$ deep, and is resolved with a nonuniform $2041 \times 481$ rectangular grid. In the horizontal direction, the model domain between 1,000 and $3,000 \mathrm{~km}$ has a high resolution of $1 \mathrm{~km}$. The two transitional zones extend $100 \mathrm{~km}$ away from the high-resolution region, where the resolution reduces from 1 to $5 \mathrm{~km}$. The grid resolution for the rest model domain where no obvious deformation occurs is $5 \mathrm{~km}$. In the vertical direction, the resolution for the upper $370 \mathrm{~km}$ is $1 \mathrm{~km}$, for the depth range $370-470 \mathrm{~km}$ reduces from 1 to $5 \mathrm{~km}$, and for the rest depth is $5 \mathrm{~km}$. Over 32 million Lagrangian markers randomly distribute in the whole model domain. These markers are moved at each time step using the computed velocity field.

The initial model consists of a 2000-km-wide weak block in the middle and two strong blocks on either side (Figure 2A). The weak block is composed of a $55-\mathrm{km}$-thick crust (a $15-\mathrm{km}$-thick upper crust, a 20 -km-thick middle crust, and a 20 -km-thick lower crust) and a $65-\mathrm{km}$-thick mantle lithosphere, representing a juvenile orogen. The strong block is composed of a $40-\mathrm{km}$ thick crust (a 20-km-thick upper crust and a 20-km-thick lower crust) and a 100-km-thick mantle lithosphere, representing a confining craton. The design of a hot orogen with a relatively thick crust allows that it is sufficiently weak and more deformable, compared to the confining cratons. A small inverted-triangular seed is imposed at the middle of the orogen crust bottom, which allows for the deformation initiating at the center of the model. The initial geotherm linearly increases from $273 \mathrm{~K}$ at the model surface to $1623 \mathrm{~K}$ at the lithosphere base. A 


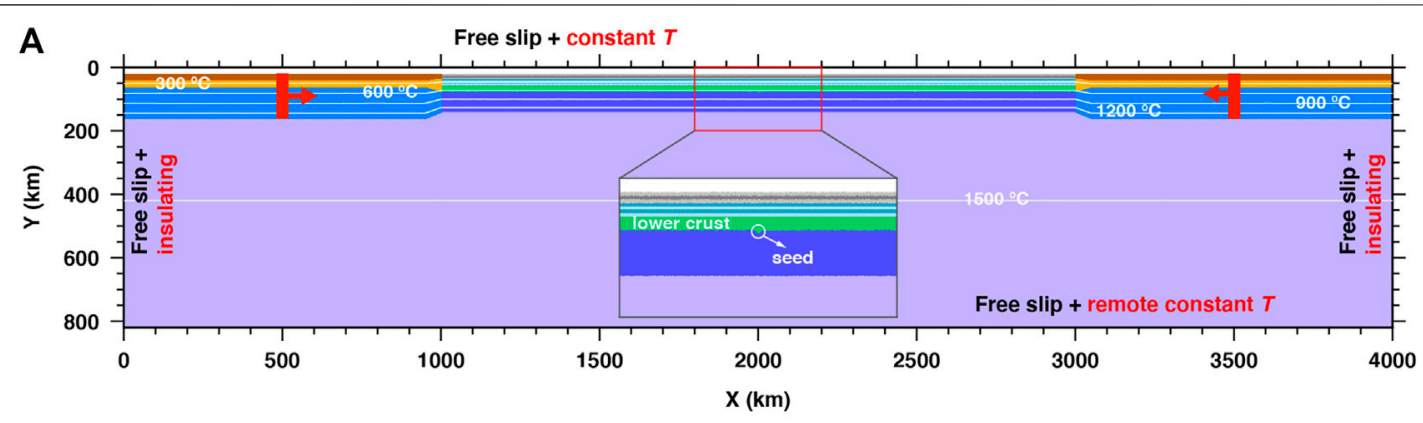

\begin{tabular}{|l|l|l|l|l|l|l|l|l|l|l|l|l|}
\hline 0 & 1 & 2 & 3 & 4 & 5 & 6 & 7 & 8 & 9 & 10 & 11 & 12 \\
\hline
\end{tabular}

B LC flow law=diorite

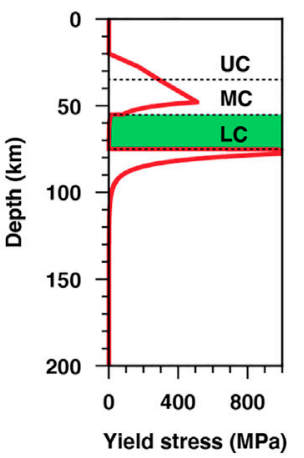

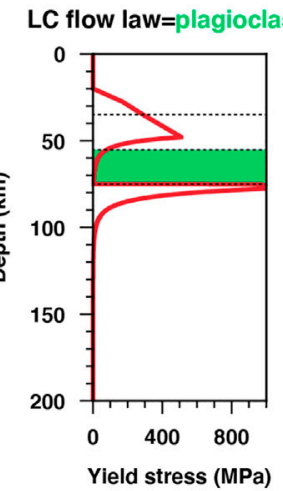

LC flow law=wet clinopyroxene

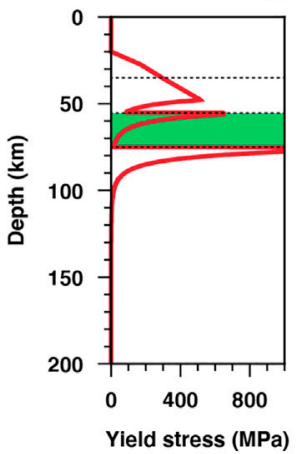

LC flow law=dry diabase

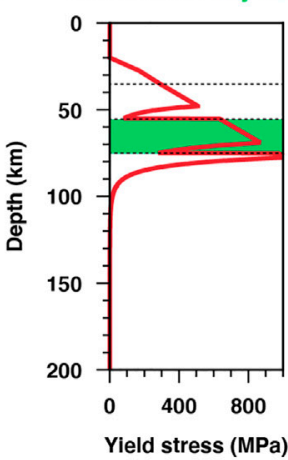

FIGURE 2 | (A) Model setup illustrating the initial model configuration and thermal-mechanical boundary conditions. The red vertical bars with lateral arrows show the locations where convergence rates are imposed. White thin lines are isotherms with an interval of $300^{\circ} \mathrm{C}$. The composition codes are: 0 , sticky air; 1 , water; 2 and 3 , orogen upper crust; 4 and 5, orogen middle crust; 6 , orogen lower crust; 7, craton upper crust; 8 , craton lower crust; 9, orogen lithosphere mantle; 10 , craton lithosphere mantle; 11, asthenosphere; 12, partially molten lower crust. (B) Lithosphere yield stress profiles for orogen lithosphere. The profiles are calculated with a constant strain rate of $10^{-16} 1 / \mathrm{s}$ and initial temperature shown in (A), both of which are variable in modeling. See Table $\mathbf{1}$ for all the rheological parameters. LC, lower crust.

mantle adiabat with potential temperature $1573 \mathrm{~K}$ and adiabatic gradient of $0.5^{\circ} \mathrm{C} / \mathrm{km}$ is used for the sub-lithosphere mantle. The mechanical boundary conditions are free slip for all the boundaries. The thermal boundary conditions are constant temperature $(273 \mathrm{~K})$ on the top, remote fixed temperature on the bottom (Gerya et al., 2006), and insulating (no horizontal heat flow) on the two sides. Horizontal shortening is implemented by imposing varying convergence rates $\left(V_{x}\right)$ at $\mathrm{X}=500 \mathrm{~km}$ and $\mathrm{X}=$ $3,500 \mathrm{~km}$ (Figure 2A).

To account for surface topographic evolution, a $20-\mathrm{km}$-thick sticky air layer is added on the top of the rocky portion of the model. It is characterized with low density $\left(1 \mathrm{~kg} / \mathrm{m}^{3}\right)$ and low viscosity $\left(10^{18} \mathrm{~Pa} \mathrm{~s}\right)$. The large density and viscosity contrast between the sticky air and rocky domain ensures small shear stresses $\left(<10^{4} \mathrm{~Pa}\right)$ along the interface and makes it an internal free surface (Schmeling et al., 2008). For simplicity, our models do not consider surface erosion and sedimentation processes.

\section{Rheology}

The strength of the lithosphere is controlled, on the geologic timescale, by the combination of both brittle and ductile deformation mechanisms. The brittle part of the lithosphere can be described by the Drucker-Prager yield criterion which expresses the linear dependence of the materials resistance on the total pressure (Gerya, 2010):

$$
\begin{gathered}
\sigma_{\text {yield }}=C+P \sin \left(\varphi_{\text {eff }}\right) \\
\sin \left(\varphi_{\text {eff }}\right)=\sin (\varphi)\left(1-\lambda_{\text {fluid }}\right) \\
\lambda_{\text {fluid }}=\frac{\mathrm{P}_{\text {fluid }}}{\mathrm{P}_{\text {total }}} \\
\eta_{\text {plastic }}=\frac{\sigma_{\text {yield }}}{2 \dot{\varepsilon}_{I I}}
\end{gathered}
$$

where $\sigma_{\text {yield }}$ is the yield stress; $P$ is the total dynamic pressure; $\mathrm{C}$ is the cohesion at $P=0 ; \varphi$ is the internal frictional angle; $\lambda_{\text {fluid }}$ is the pore fluid pressure factor that reduces the yield strength of fluidcontaining porous or fractured rocks; $\dot{\varepsilon}_{I I}=\left(0.5 \dot{\varepsilon}_{i j} \dot{\varepsilon}_{i j}\right)^{1 / 2}$ is the second invariant of the strain rate tensor; $\eta_{\text {plastic }}$ is the viscosity for plastic rheology. $\varphi_{\text {eff }}$ can be illustrated as the effective internal frictional angle that integrates the effects of internal frictional angle and pore fluid coefficient. In the modeling, a cohesion of $1 \mathrm{MPa}$ is used for all the material. $\sin (\varphi)=0$ is used for the air, water and partially molten rocks, $\sin (\varphi)=0.15$ for all the solid crust rocks, and $\sin (\varphi)=0.6$ for all the mantle rocks.

The viscosity for ductile creep is given by (Hirth and Kohlstedt, 2003): 
TABLE 1 | Rheological parameters of material used in this study ${ }^{a}$.

\begin{tabular}{|c|c|c|c|c|c|c|c|}
\hline Material & Flow law & $A_{D}\left(M P a^{-n} s^{-1}\right)$ & $\mathbf{n}$ & $r$ & $E_{a}(k J / m o l)$ & $\mathrm{V}_{\mathrm{a}}\left(\mathrm{cm}^{3} / \mathrm{mol}\right)$ & References \\
\hline Air & N.A. & - & - & - & - & - & - \\
\hline Water & N.A. & - & - & - & - & - & - \\
\hline UCC & Wet quartzite & $3.2 \times 10^{-4}$ & 2.3 & - & 154 & - & 1 \\
\hline LM & Dry olivine & $2.5 \times 10^{4}$ & 3.5 & - & 532 & 12 & 1 \\
\hline AM & Dry olivine & $2.5 \times 10^{4}$ & 3.5 & - & 532 & 12 & 1 \\
\hline MCC & Plagioclase $A n_{75}$ & $3.3 \times 10^{-4}$ & 3.2 & - & 238 & 8 & 1 \\
\hline LCC1 & Plagioclase $A n_{75}$ & $3.3 \times 10^{-4}$ & 3.2 & - & 238 & 8 & 1 \\
\hline LCC2 & Diorite & $3.8 \times 10^{-2}$ & 2.4 & - & 219 & - & 2 \\
\hline LCC3 & Mafic granulite & $1.0 \times 10^{-2}$ & 3.2 & - & 244 & - & 3 \\
\hline LCC4 & Wet anorthite & $3.98 \times 10^{2}$ & 3.0 & - & 356 & - & 4 \\
\hline LCC5 & Dry anorthite & $5.0 \times 10^{12}$ & 3.0 & 0 & 648 & 24 & 4 \\
\hline LCC6 & Wet cpx & $1.0 \times 10^{-2}$ & 3.5 & - & 310 & - & 5 \\
\hline LCC7 & Dry cpx & 31.6 & 4.2 & 0 & 413 & - & 6 \\
\hline LCC8 & Gabbro & $2.0 \times 10^{10}$ & 4.0 & 0 & 644 & - & 7 \\
\hline LCC9 & Dry diabase & 8 & 4.7 & 0 & 485 & - & 8 \\
\hline
\end{tabular}

${ }^{a}$ For material: UCC, upper continental crust; MCC, middle continental crust; LCC, lower continental crust; LM, lithospheric mantle; AM, asthenospheric mantle. For references: 1 , Ranalli (1995); 2, Hansen (1982); 3, Wang et al. (2012); 4, Rybacki and Dresen (2000); 5, Zhang et al. (2006); 6, Moghadam et al. (2010); 7, Zhou et al. (2012); 8, Mackwell et al. (1998).

$$
\eta_{\text {ductile }}=\left(\dot{\varepsilon}_{I I}\right)^{(1-n) / n} A_{D}^{-1 / n} C_{O H}^{-r / n} \exp \left(\frac{E_{a}+P V_{a}}{n R T}\right)
$$

where $A_{D}$ (material constant), $E_{a}$ (activation energy), $V_{a}$ (activation volume), $n$ (stress exponent) are experimentally determined flow law parameters. $\mathrm{C}_{\mathrm{OH}}$ is the water content in ppm H/Si, $r$ is the water content exponent (Hirth and Kohlstedt, 2003), $R$ is the gas constant, and $T$ is the absolute temperature. The rheological parameters $\left(A_{D}, E_{a}, V_{a}, n\right)$ are derived from laboratory studies of deformation of rocks.

The effective viscosity is determined by comparing brittle/ plastic and creep viscosities as a function of depth (Ranalli, 1995):

$$
\eta_{\text {eff }}=\min \left\{\eta_{\text {plastic }}, \eta_{\text {ductile }}\right\}
$$

The application of laboratory-derived rheological parameters to deformation at geological time and space scales needs to extrapolate the laboratory strain rates over many orders of magnitudes. Burgmann and Dresen (2008) show that laboratory-based rheologies are well consistent with geodetic measurement and field observations, indicating that laboratory-derived rheologies can be used as a good description of geological deformation. However, there is significant uncertainty in the laboratory-derived rheologies of the continental lower crust. For example, the lower crust yield stress calculated with the laboratory-derived flow laws of "diorite" and "plagioclase" (Ranalli, 1995) is less than $100 \mathrm{MPa}$ under the model condition (Figure 2B). When I use "wet clinopyroxene" (Zhang et al., 2006) or "diabase" (Mackwell et al., 1998) as the lower crust flow law, the yield stress reaches several hundreds of $\mathrm{MPa}$.

In the modeling, the rock rheologies are based on the laboratory-established flow laws. In all models, I use a "wet quartzite" flow law for the continental upper crust, "plagioclase An75" for the craton lower crust and orogen middle crust, and "dry olivine" for the lithospheric and asthenospheric mantle (Ranalli, 1995). I examine changes in the orogen lower crust rheology by varying the laboratory- derived flow laws. All partially molten rocks are assigned to a reduced effective viscosity of $10^{18} \mathrm{~Pa}$ s (Pinkerton and Stevenson, 1992) which provides large viscosity contrast with the surrounding solid rocks. Table 1 lists the rheological parameters tested in this study.

\section{MODELING RESULTS}

I conducted ten numerical simulations by varying the lower crust flow law and convergence rate. Three distinct modes of model deformation have been identified: 1) lithosphere mantle delamination, 2) localized thickening, and 3) lithospheric mantle underthrusting. Table 2 shows a summary of all the simulations.

\section{Reference Model: Weak Lower Crust and Delamination}

Figure 3 shows the evolution of the model "dela" (see Table 2). This model uses a lower crust flow law of "diorite" and a half convergence rate of $2.5 \mathrm{~cm} / \mathrm{yr}$. The convergence of the strong cratonic lithosphere causes the orogen to undergo pure shear shortening. After $5 \mathrm{Myr}$ of convergence ( $250 \mathrm{~km}$ of shortening), lithospheric thickening preferentially occurs at the center of the model (Figure 3Ai). Owing to the notably low viscosity of the orogen lower crust relative to its upper and lower layer, the upper crust is decoupled from the lithosphere mantle (Figure 3Aii). By $14 \mathrm{Myr}$ of shortening $(700 \mathrm{~km})$, the orogen crust experiences marked folding and buckling, forming a number of $\mathrm{V}$-shape strain localizations, and has a thickness of $\sim 70 \mathrm{~km}$ (Figure 3B). However, the orogen lithosphere mantle thickening does not concur with the crust. Convergence forces the orogen lithosphere mantle to slide along the weak orogen lower crust and sink downward at the middle of the model (Figure 3B), resulting in a large piece of downwelling similar to the two-sided subduction shown by Gerya et al. (2008). The downwelling undergoes 
TABLE 2 | Parameters and Results of Conducted Experiments ${ }^{a}$.

\begin{tabular}{|c|c|c|c|c|}
\hline Model name & $V_{x}(\mathrm{~cm} / \mathrm{a})$ & OLC flow law & Figures & Comments \\
\hline dela & 2.5 & Diorite & $2,3,6$ & Delamination \\
\hline delb & 2.5 & Mafic granulite & 7,8 & Delamination \\
\hline delc & 2.5 & Plagioclase An75 & 4,6 & Localized thickening \\
\hline deld & 2.5 & Wet clinopyroxene & - & Localized thickening \\
\hline dele & 2.5 & Wet anorthite & - & Localized thickening \\
\hline delf & 2.5 & Dry diabase & 5,6 & Underthrusting \\
\hline delg & 2.5 & Dry clinopyroxene & - & Underthrusting \\
\hline delh & 2.5 & Dry anorthite & - & Underthrusting \\
\hline deli & 2.5 & Gabbro & - & Underthrusting \\
\hline delj & 1.0 & Mafic granulite & 7,8 & Delamination \\
\hline
\end{tabular}

${ }^{a} \boldsymbol{V}_{\boldsymbol{x}}$, convergence rate. OLC, orogen lower crust.

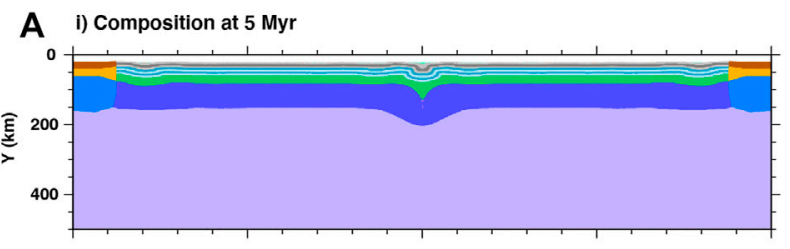

B i) Composition at $14 \mathrm{Myr}$

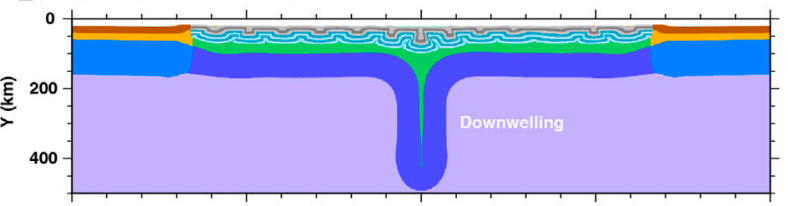

C i) Composition at $14.7 \mathrm{Myr}$

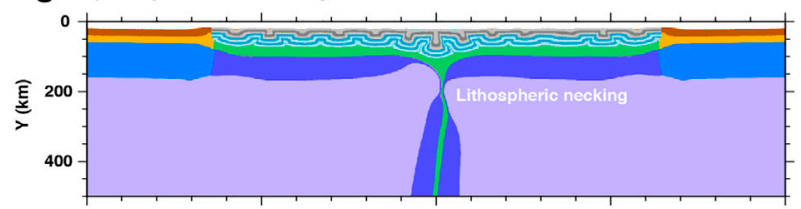

D i) Composition at $19.9 \mathrm{Myr}$

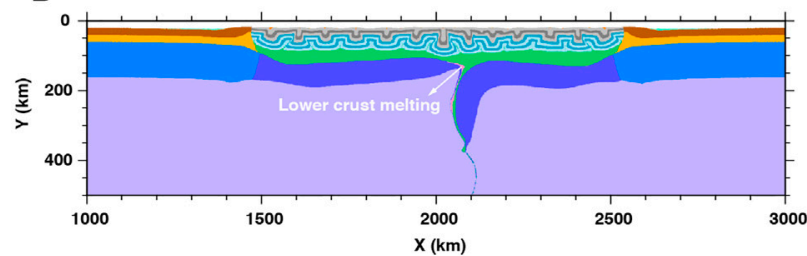

ii) Viscosity at $5 \mathrm{Myr}$

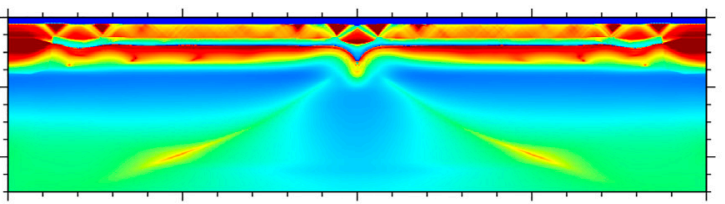

ii) Viscosity at $14 \mathrm{Myr}$

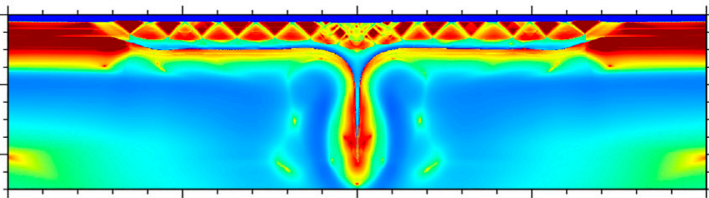

ii) Viscosity at $14.7 \mathrm{Myr}$

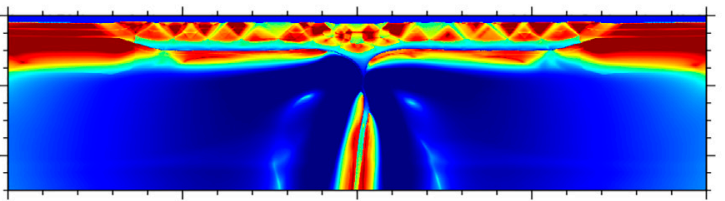

ii) Viscosity at $19.9 \mathrm{Myr}$

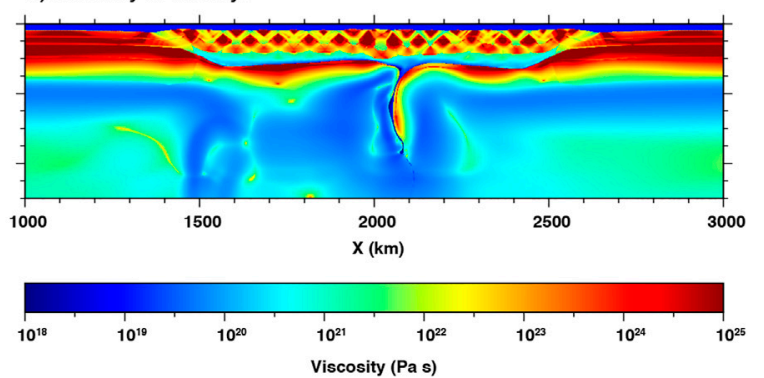

FIGURE 3|Time evolution of the model "dela", in which the orogen lower crust rheology is represented by the flow law of diorite. (Ai-Di) composition evolution for selected model times (colors as in Figure 2). (Aii-Dii) viscosity distribution for selected model times. Note the extremely low viscosity in the upper mantle shown in (Cii) is due to the presence of very large velocities as the downwelling breaks off.

necking in a short time span $(<1 \mathrm{Myr})$ due to its negative buoyancy, and finally breaks off from the orogen crust (Figure 3C), which I refer to as delamination. The delamination of the lithosphere mantle makes the orogen crust expose directly to the asthenosphere, leading to partial melting of the lower crust (Figure 3D). The replacement of the lower crust flow law with "mafic granulite" (Wang et al., 2012) does not change the overall behavior (see Effects of Convergence Rate). This is because both "diorite" and "granulite" fall into the weak end of the lower crust rheology (Figure 1). Note the flow law "mafic granulite" presented by Wang et al. (2012) is significantly weaker than the early one presented by Wilks and Carter (1990) due to different experimental samples and conditions (see Wen et al., 2021 for details). 


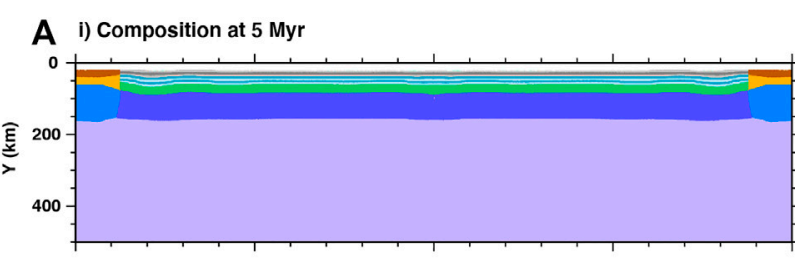

B i) Composition at 14.2 Myr

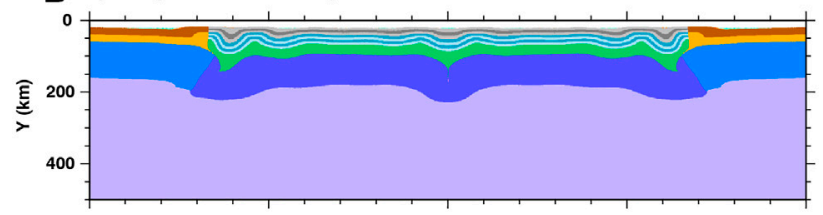

C i) Composition at $20 \mathrm{Myr}$

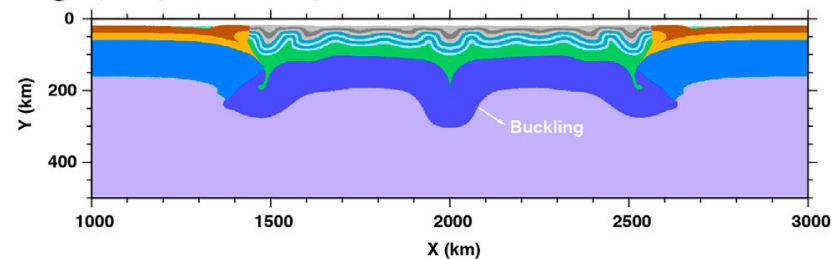

ii) Viscosity at $5 \mathrm{Myr}$

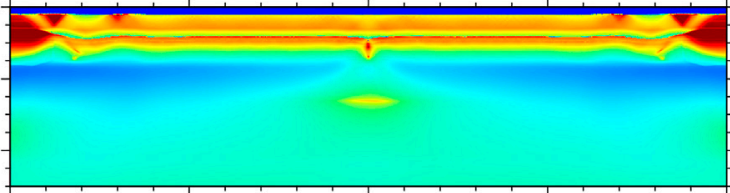

ii) Viscosity at $14.2 \mathrm{Myr}$

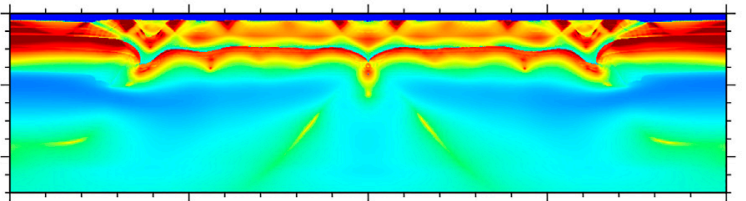

ii) Viscosity at $20 \mathrm{Myr}$

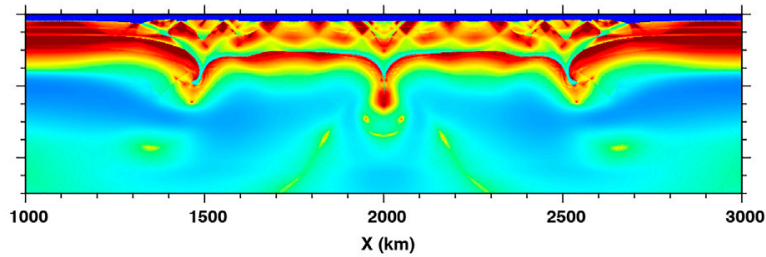

FIGURE 4 | Time evolution of the model "delc", in which the orogen lower crust rheology is represented by "plagioclase". (Ai-C) composition evolution for selected model times (colors as in Figure 2). (Aii-Cii) viscosity distribution for selected model times (colors as in Figure 3).

\section{Intermediately Strong Lower Crust and Localized Thickening}

This model ("delc" in Table 2) differs from the reference model only in that the flow law of the orogen lower crust is changed to "plagioclase", representing an intermediately strong lower crust. Because the viscosity of the orogen lower crust increases relative to that in the reference model, lithospheric thickening is no longer concentrated only at the center of the model (Figure 4A). Instead, localized thickening occurs at the orogen edges and center, forming three separate lithospheric bulges (Figure 4B). After 20 Myr of convergence, the strong craton lithosphere indents into the orogen lithosphere (Figure 4C). In comparison to the reference model, crustal folding and buckling are less pronounced. Localized thickening accommodates most of the horizontal shortening, but thickened lithosphere mantle remains below the orogen.

\section{Strong Lower Crust and Underthrusting}

In this model ("delf" in Table 2), "diabase" is used as the flow law of the orogen lower crust and the other parameters are identical to those in the reference model. As mentioned above, the "diabase" flow law represents the strong end member of the lower crust rheology according to the available laboratory results (Figure 1). By $5 \mathrm{Myr}$ of convergence $(250 \mathrm{~km})$, horizontal shortening first causes the whole orogen lithosphere to fold in a wavy manner with a wavelength of $\sim 250 \mathrm{~km}$ (Figure 5A). With continued convergence, orogen crust folding becomes more pronounced and the strong craton lithosphere starts to underthrust below the orogen (Figure 5B). In contrast to the reference model, no localized lithospheric thickening occurs in this model owing to enhanced resistance of the orogen to shortening. By 20.4 Myr of convergence ( 1,000 km), the wavelength of folding decreases to $\sim 200 \mathrm{~km}$ and the strong craton lithosphere subducts beneath the orogen at both sides. In this case, horizontal shortening is mainly accommodated by underthrusting of craton mantle lithosphere below the orogen, and orogen crustal thickening only plays a secondary role due to its high strength.

\section{Topographic Evolution}

The surface response of lithosphere to convergence is associated with the strength of the crust, in the models. Figure 6 shows the comparison of the topography evolutions predicted by the above models. In the weak lower crust case (Figure 6A), the central region of the orogen first subsides below the sea level with an amplitude of $\sim 4 \mathrm{~km}$. This is resulted from the loading on the surface of the denscending mantle lithosphere beneath the orogen center. Topography highs at sides of the orogen arise from the compression between the craton and orogen. By $14.7 \mathrm{Myr}$, the downwelling mantle lithosphere breaks off and sinks into the deep mantle (see Figure 3C). This results in an abrupt rebound of the central depression, rapidly attaining an elevation of $\sim 2 \mathrm{~km}$ (Figure 6aii). The negative surface defection neighboring the topography highs at the sides of the orogen reaches $\sim 4 \mathrm{~km}$, forming two foreland deeps. After $20 \mathrm{Myr}$ of convergence, the orogen is characterized by three marked topography highs with two at boundaries and one at the central region, reaching $\sim 4,000 \mathrm{~m}$, while a large area remains flat with no elevation. The surface expression of the intermediately strong orogen to horizontal shortening is different from the weak case (Figure 6B). Because neither wholesale mantle lithosphere descending nor delamination occurs in this case, the central region of the deformed area does not change significantly, and 


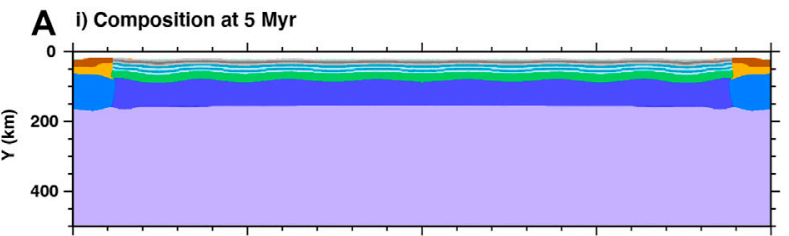

\section{B i) Composition at 14.2 My}

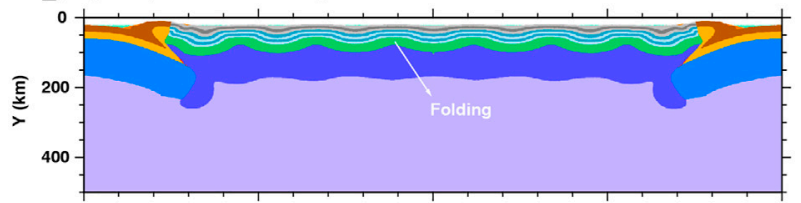

C i) Composition at $20.4 \mathrm{Myr}$

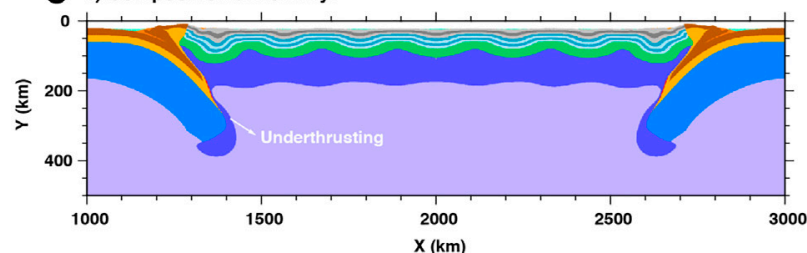

\section{ii) Viscosity at $5 \mathrm{Myr}$}

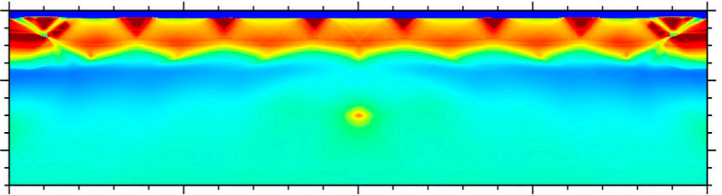

ii) Viscosity at 14.2 Myr

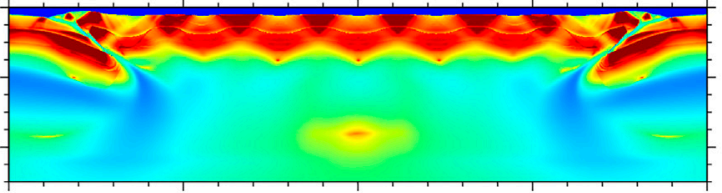

ii) Viscosity at $20.4 \mathrm{Myr}$

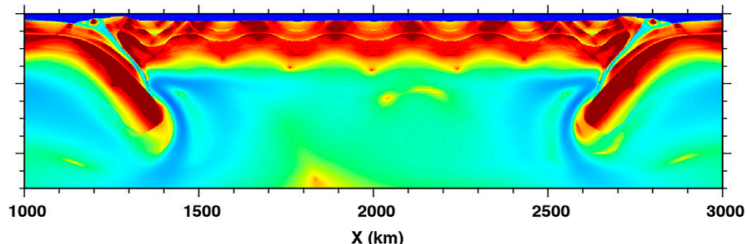

FIGURE 5 | Time evolution of the model "delf", in which the orogen lower crust rheology is represented by 'diabase'. (Ai-Ci) composition evolution for selected model times (colors as in Figure 2). (Aii-Cii) viscosity distribution for selected model times (colors as in Figure 3).

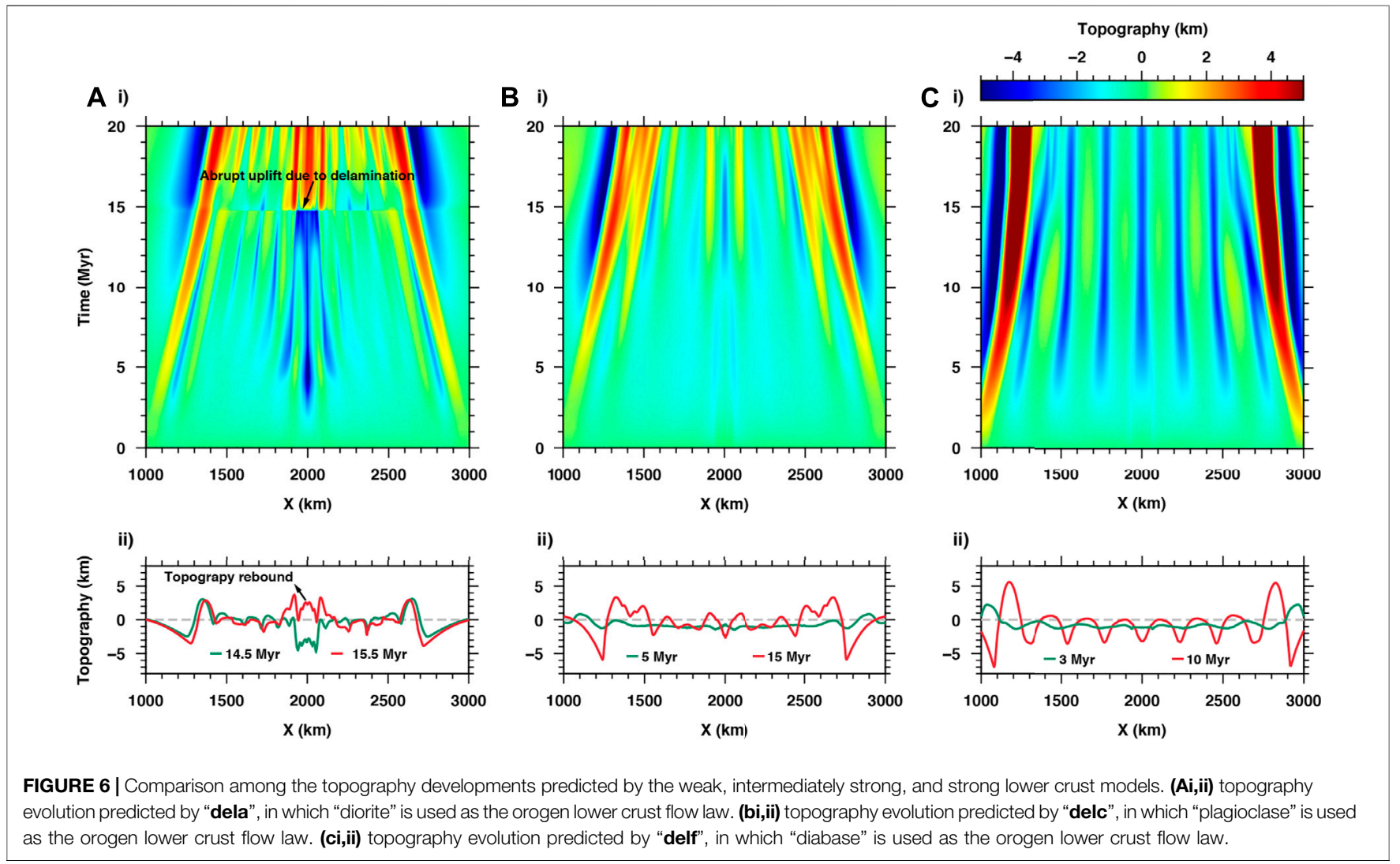



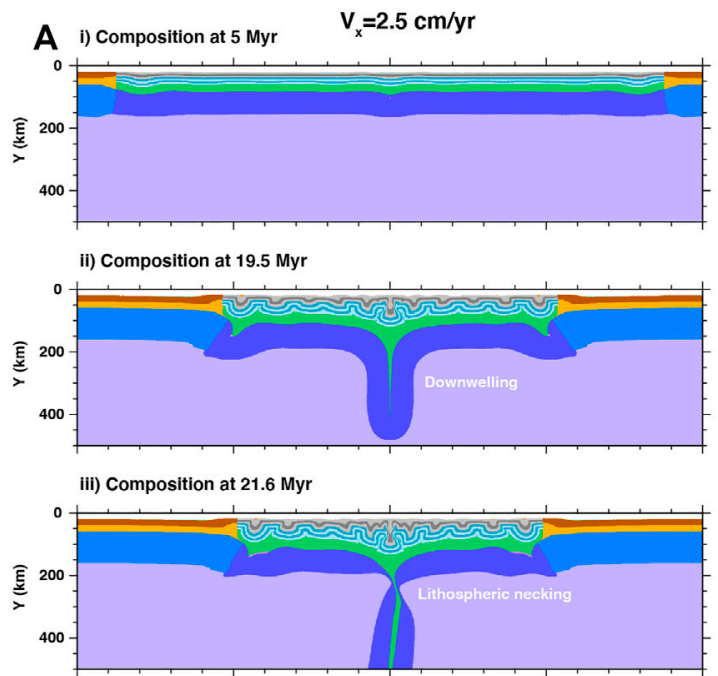

iv) Composition at $28.2 \mathrm{Myr}$

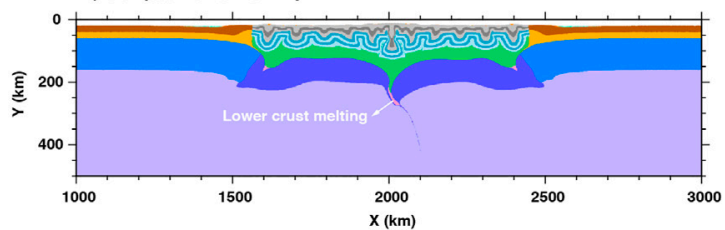

B i) Composition at $11.6 \mathrm{Myr} \quad \mathrm{V}_{\mathrm{x}}=\mathbf{1 . 0 \mathrm { cm } / \mathrm { yr }}$

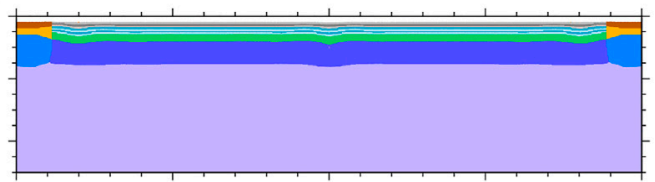

ii) Composition at 39.2 Myr

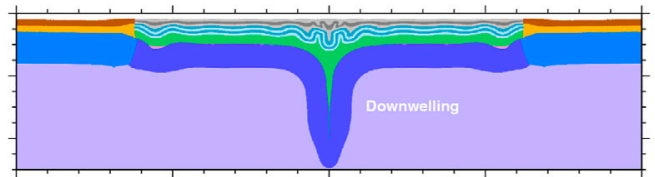

iii) Composition at $40.8 \mathrm{Myr}$

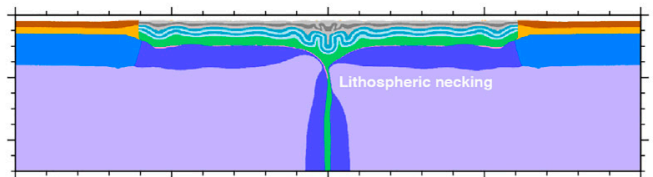

iv) Composition at $49.8 \mathrm{Myr}$

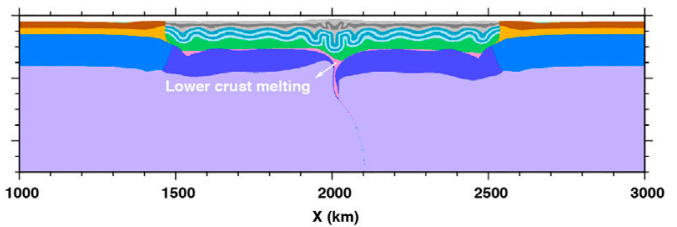

FIGURE 7 | Time evolutions of the models with different convergence rates. (A) fast convergence model $\left(V_{x}=2.5 \mathrm{~cm} / \mathrm{yr} ;\right.$ see "delb" in Table 2), and (B) slow convergence model $\left(V_{x}=1.0 \mathrm{~cm} / \mathrm{yr}\right.$; see "delj" in Table 2). The flow law of "mafic granulite" (Wang et al., 2012) is used for the orogen lower crust in these models.

A

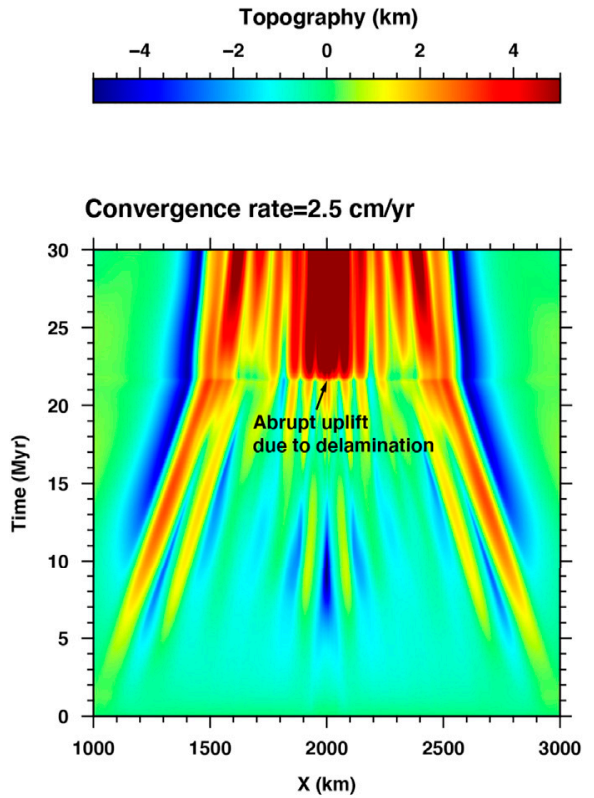

B Convergence rate $=1.0 \mathrm{~cm} / \mathrm{yr}$

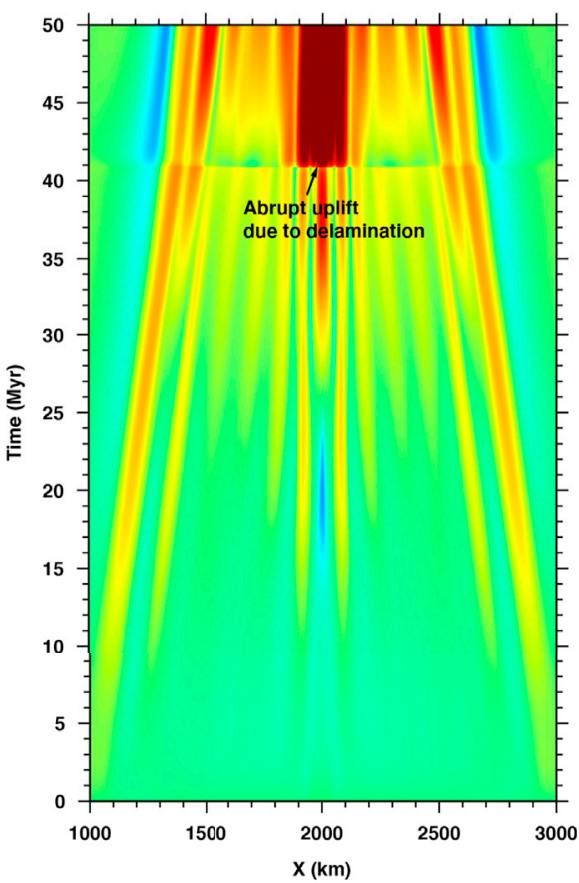

FIGURE 8 | Topography evolutions predicted by the fast convergence model "delb" B and slow convergence model "delj" (B). 


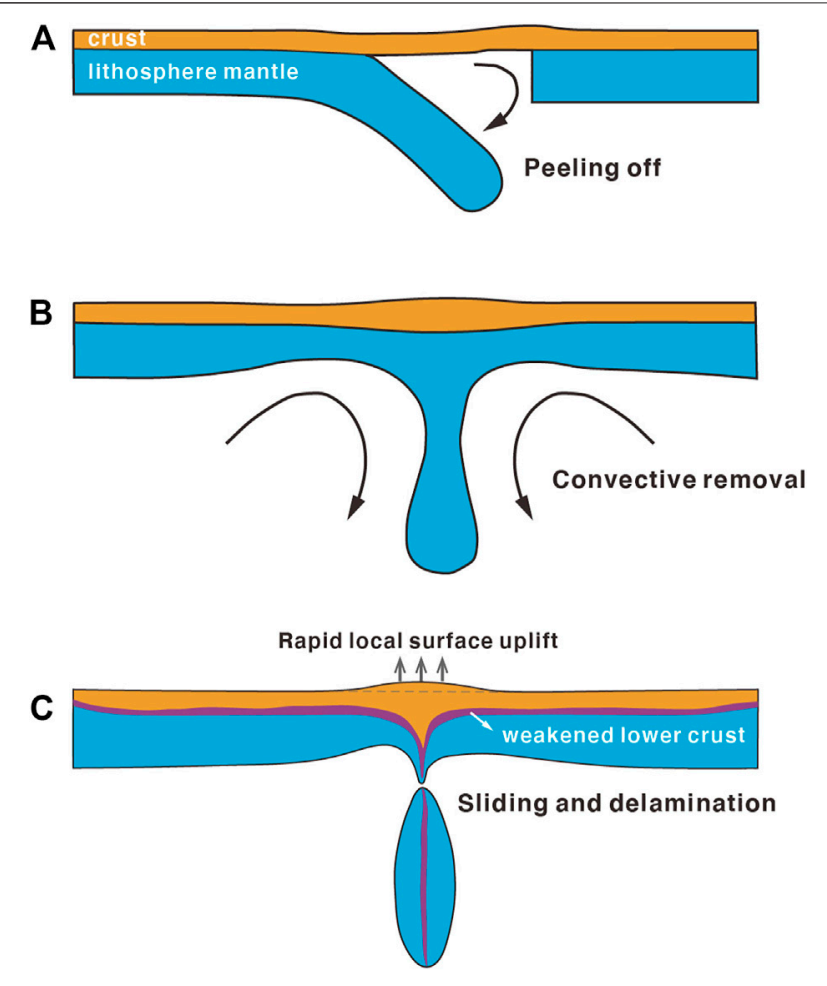

FIGURE 9 | Schematic illustration of three types of lithosphere mantle removal during collisional orogeny. (A) Conventional delamination model (Bird, 1979). (B) Convective removal via Rayleigh-Taylor instability (Houseman et al., 1981). (C) Weakened lower crust-assisted delamination.

does not develop topography. By 20 Myr, two topography highs, which has a width of $\sim 200 \mathrm{~km}$ and an elevation of $\sim 4 \mathrm{~km}$, develop at both sides of the orogen. In contrast, the orogen interior is relatively flat and remains low. In the strong orogen case (Figure 6C), two notable topography highs also develop at the orogen sides. They are very high in comparison to the weak and intermediately strong cases, which I ascribe to the absence of erosion in the models. Interestingly, the region bounded by the two topography highs alternates between negative and positive surface deflection, forming a couple of evenly-spaced topographic ribbons. Most of the undulated surface is close to or below the sea level, thus they have potential to be infilled with the material eroded from the two topography highs.

In summary, the topography expression during collisional orogeny depends on the strength of the orogen itself. The above-mentioned topographic features can be used as surface diagnostics to distinguish the nature of orogeny.

\section{Effects of Convergence Rate}

The convergence rate has an important control on the deformation of the lithosphere. With increasing convergence velocity, the response of the weak lithosphere shifts towards the response of a stiff lithosphere, although delamination occurs nevertheless.

Figure 7 compares the evolution of the orogen shortened by different convergence rates, showing that, for the same rheology, the evolution stages are the same, yet occurs at different times. In these two models ("delb" and "delj" in Table 2), "mafic granulite" is used as the flow law of the orogen lower crust and the other parameters keep the same as those in the reference model. At the early stage of convergence, all experiments show a similar deformation behavior, which are comparable to the weak crust model presented before. The differences become remarkable when the amount of convergence exceeds $\sim 500 \mathrm{~km}$. For a fast convergence rate $\left(\mathrm{V}_{\mathrm{x}}=\right.$ $2.5 \mathrm{~cm} / \mathrm{yr}$; see Figure 7A), the amount of convergence required for lithospheric mantle delamination is $\sim 1,080 \mathrm{~km}$, which occurs after $22 \mathrm{Myr}$ from the model start. When a slower convergence rate is used $\left(\mathrm{V}_{\mathrm{x}}=1.0 \mathrm{~cm} / \mathrm{yr}\right.$; see Figure $\left.7 \mathrm{~B}\right)$, the amount of convergence required decreases to $\sim 820 \mathrm{~km}$, and delamination occurs at $41 \mathrm{Myr}$ from the model start. Thus, the slower the convergence rate, the later the delamination occurs, and the less convergence is required to reach similar geodynamic outcomes. This second-order difference is due to the considerably greater volume of the lower crustal melting in the slow convergence, enhanced by larger radiogenic heating. The slower convergence enhances the crustal flow and inhibit folding and faulting (Figure 7). Therefore, a faster convergence generates a more rugged topography throughout the evolution of the models, while a slower convergence produces a relatively smoother topography (Figure 8).

\section{DISCUSSION}

\section{Comparisons With Previous Delamination Modeling}

The models predict that the orogen lithosphere mantle is removed as a coherent slice in response to horizontal shortening when the lower crust is sufficiently weak (e.g., Figures 3, 7). This differs both from the conventional delamination model and convective removal model (Figure 9). The former argues that the lithosphere mantle peels away from the crust via an elongated conduit (Bird, 1979; see Figure 9A), and the latter suggests the cold and dense lithosphere mantle drips off in an un-plate-like manner (e.g., Houseman et al., 1981; see Figure 9B). In the new delamination model presented here, it is the weak lower crust that plays a critical role in decoupling the deformation of the upper crust and lithosphere mantle and detaching of the thickened lithosphere mantle as a coherent slab (Figure 9C). The weak lower crust acts like a lubricant which decouples the deformation of the orogen's upper crust from its lithosphere mantle, allows sliding of the lithosphere mantle along the base of the crust, and promotes delamination of the lithosphere mantle as a coherent slice. Once a large scale lithospheric downwelling is formed, the delamination process occurs rapidly and can be completed in $2 \mathrm{Myr}$, which is much more efficient than the manner of viscous dripping ( $25 \mathrm{Myr}$; see Gogus and Pysklywec, 2008). In addition, the punctuated surface uplift due to lithosphere delamination is limited to a localized area ( $200-\mathrm{km}$ wide) above the delaminated lithosphere, not in a broad region as previously demonstrated (e.g., Gogus and Pysklywec, 2008). Because the convergence is imposed at both sides of the orogen, the elevated region is not mobile as shown by Krystopowicz and Currie (2013), but becomes narrow as the 

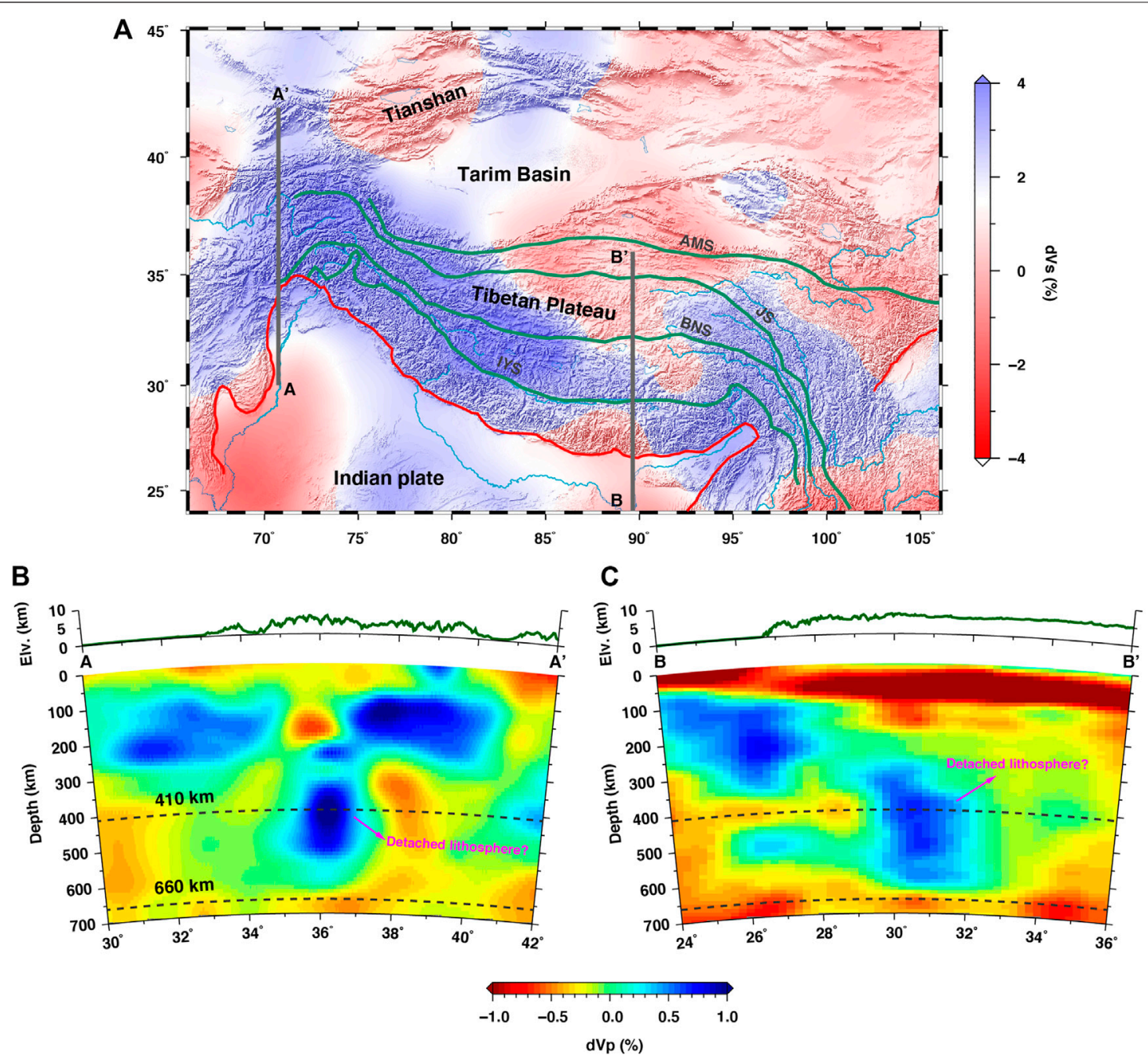

FIGURE 10 ( (A) Average S-wave velocity anomalies between 75 and $375 \mathrm{~km}$ depth in the Tibetan plateau. The data are from Schaeffer and Lebedev (2013). (B,C) P-wave velocity variations at two cross sections, showing subvertical high-velocity structures in the upper mantle. The locations of the cross sections are shown in (A) The data are from Li et al. (2008). Dark green curves indicate suture zones within the Tibetan plateau (Taylor and Yin, 2009). See Figure 1 for abbreviations.

convergence proceeds. A comprehensive investigation of the surface expression resulted from delamination will be presented elsewhere.

\section{Implications for Tibetan Mantle Dynamics}

In this section, I apply the model results to understanding the mantle dynamics of the Tibetan Plateau. Because the models are not specially designed for the Tibetan plateau, the comparisons are only made in an intuitive and qualitative way.

While the Tibetan crust has been uniformly thickened to double normal thickness throughout the India-Asia convergence, the Tibetan mantle lithosphere underwent a more complex evolution. According to tectonic reconstructions, $\sim 1,000 \mathrm{~km}$ of north-south shortening at least, including the eastward extrusion, is accommodated by the Tibetan crust (Guillot et al., 2003; Replumaz and Tapponnier,
2003). This implies an equal amount of mantle lithosphere to be accommodated beneath the Tibetan plateau, which is proposed in the frame of two different scenarios. One suggests that the shortened lithosphere mantle is found beneath the plateau, i.e., it has not detached (Priestley et al., 2006). Evidence for this comes from a multimode surface waveform tomography study, showing high-velocity and cold material underlying most of Tibet to a depth of $225-250 \mathrm{~km}$ (Priestley et al., 2006). The other scenario invokes convective removal of Tibet's thickened mantle and its replacement by a hot asthenosphere (Molnar et al., 1993; Turner et al., 1993). This inference is mainly based on the inefficient $\mathrm{Sn}$ propagation and low Pn velocities observed beneath northern Tibet (Barazangi and Ni, 1982; McNamara et al., 1995; McNamara et al., 1997).

Recent seismic studies reveal that the mantle lithosphere under the Tibetan plateau is strongly heterogeneous 
(Figure 10). P-wave travel time tomography reveals low speeds in the shallow mantle beneath much of central and eastern Tibet and decrease of the horizontal distance over which the Indian lithosphere slides northward beneath the plateau from west to east (Li et al., 2008). Surface wave studies show that shear-wave speeds within the mantle lithosphere are high beneath western and southwestern Tibet and low beneath central and eastern Tibet (Agius and Lebedev, 2013; Schaeffer and Lebedev, 2013), suggesting the Tibetan lithosphere is cold and thick in western Tibet and warm and thin in central and eastern Tibet. More recently, Chen et al. (2017) showed a T-shaped high wave speed structure beneath southern to central Tibet using adjoint seismic tomography method and interpreted it as an upper mantle remnant from earlier lithospheric foundering. More detailed P-wave travel time tomography from INDEPTH II and III data reveals a subvertical high-velocity structure extending to $\sim 400 \mathrm{~km}$ beneath southern Tibet, north of the Yarlung-Zangbo suture, which was interpreted as downwelling Indian mantle lithosphere (Tilmann and $\mathrm{Ni}, 2003$ ). Such a high-velocity anomaly has been confirmed by the global $\mathrm{P}$ wave tomographic model (Li et al., 2008; also see Figure 10). A similar subvertical high-velocity structure was also observed beneath the western syntaxis of the India-Asia collision zone (Negredo et al., 2007; also see Figure 10). In addition, recent S receiver function results reveal a thin Tibetan lithosphere $(\sim 100 \mathrm{~km}$ depth) overriding a northward subducting Indian lithosphere $(\sim 250 \mathrm{~km})$ and a southward subducting Asian lithosphere $(\sim 200 \mathrm{~km})$ (Zhao et al., 2011). This indicates strong heterogeneities and rules out a uniform lithosphere, as Priestley et al. (2006) suggested.

According to the model results, how the mantle lithosphere is accommodated during horizontal shortening is associated with the lower crust rheology. At the early stage of the IndiaAsia convergence, the Tibetan crust underwent minor shortening and was not thickened significantly. The widespread Cretaceous and Palaeocene red bed sediments covering much of Tibet (e.g., Yin, 2010) provides evidence for the Tibetan crust having a normal thickness at that time, although pre-collision crustal thickening possibly occurred in the southern Lhasa terrane (Murphy et al., 1997; Kapp et al., 2005). Thus, the crust beneath Tibet remained relatively cold and strong, allowing for transmitting the Indian horizontal forces to the far north. The accommodation of the lithosphere mantle shortening mainly takes the form of strong lithosphere subducting on both sides of Tibet, just like the case showed in the model "indf" (Figure 5). This is consistent with the $\mathrm{P}$ or $\mathrm{S}$ receiver function results showing northward subduction of India beneath southern Tibet and southward subduction of Asia beneath northeastern (Kind et al., 2002; Kumar et al., 2006; Zhao et al., 2011. The model results show that the deformation of the northern margins of Tibet can be explained with a relatively strong Asian crust at the early stage of convergence.

As the Tibetan crust was thickened close to the present values, the lower crust becomes hotter and weaker owing to shear and radioactive heating (e.g., Chen et al., 2019). The high conductivity zones imaged by magnetotelluric studies in northern and eastern Tibet have been interpreted as widespread partial melt with the lower crust (Wei, 2001; Bai et al., 2010), which provides relevant support for its rheologically weak state. A rheologically weak lower crust can facilitates decoupling of the crust and lithosphere mantle and local downwelling of the lithosphere mantle, as demonstrated by the model "dela" (Figure 3). Therefore, I speculate that the progressive heating of the thickened crust would lead to crustal weakening and induce the delamination of the lithospheric mantle at the later stage of the Tibetan Plateau evolution. The subvertical high-velocity structures seen in southern Tibet and western Himalayan syntax (Figure 9) may exemplify localized downwelling of orogen mantle lithosphere steered by a rheologically weak lower crust. As shown in Figure 6, the delamination of the downwelling lithosphere mantle would result in a local, not broad, surface uplift. This process possibly explains a proto-Tibetan plateau first uplifted in central Tibet by $40 \mathrm{Ma}$ ago (Wang et al., 2008).

\section{CONCLUSION}

In this study, I investigate the role of the lower crust rheology and convergence velocity based on a range of laboratory-derived flow laws in collisional orogeny using 2-D thermomechanical modeling method. I have drawn the following conclusions:

1) The lower crust strength and velocity are critical factors controlling how the orogen lithosphere mantle is accommodated during horizontal shortening. If the lower crust is extremely weak, the upper portion of the orogen crust decouples from the mantle lithosphere. Crustal folding and buckling are accompanied by localized downwelling of the mantle lithosphere, followed by detachment as a coherent slab. Conversely, if the lower crust rheology is represented by strong end-member of flow laws (e.g., diabase), the convergence is accommodated by underthrusting of the strong block lithospheres on both sides of the orogen. For an intermediately strong lower crust (e.g., plagioclase), concurrent thickening of the orogen crust and mantle lithosphere at the middle and sides of the orogen accommodates most of convergence, and thickened mantle lithosphere remains below the orogen.

2) The surface expression of an orogen subjected to horizontal shortening depends on the strength of the orogen itself. For a weak orogen, topography highs first develop at orogenic margins. The rise of the central region, resulted from lithosphere delamination, postdates the uplift of the margins. In contrast, topography highs only form at the orogenic margins for a strong orogen, and no punctuated surface uplift occurs in the orogen's interior.

3) When compared to the Tibetan plateau, I suggest that the subvertical high-velocity structures, as revealed by seismic tomography studies in southern Tibet and western syntax, possibly exemplify localized delaminating of the thickened mantle lithosphere owing to rheological weakening of the lower crust during the India-Asia convergence. 


\section{DATA AVAILABILITY STATEMENT}

The original contributions presented in the study are included in the article/Supplementary Material, further inquiries can be directed to the corresponding author.

\section{AUTHOR CONTRIBUTIONS}

LC designed the study, run all the models, and wrote the paper.

\section{FUNDING}

This research is supported by the National Natural Science Foundation of China (91955311, 41888101, and 41974110). The simulations were run on the TianHe-1A cluster at National Supercomputer Center in Tianjin and Supercomputing Laboratory at IGGCAS. The model output data used to generate the plots are provided in Zenodo (https://doi.org/10.5281/zenodo.5171512).

\section{REFERENCES}

Agius, M. R., and Lebedev, S. (2013). Tibetan and Indian Lithospheres in the Upper Mantle beneath Tibet: Evidence from Broadband Surface-Wave Dispersion. Geochem. Geophys. Geosyst. 14 (10), 4260-4281. doi:10.1002/ ggge.20274

Bai, D., Unsworth, M. J., Meju, M. A., Ma, X., Teng, J., Kong, X., et al. (2010). Crustal Deformation of the Eastern Tibetan Plateau Revealed by Magnetotelluric Imaging. Nat. Geosci. 3 (5), 358-362. doi:10.1038/ngeo830

Bajolet, F., Galeano, J., Funiciello, F., Moroni, M., Negredo, A.-M., and Faccenna, C. (2012). Continental Delamination: Insights from Laboratory Models. Geochem. Geophys. Geosyst. 13, a-n. doi:10.1029/ 2011 GC003896

Barazangi, M., and Ni, J. (1982). Velocities and Propagation Characteristics of Pn and Sn beneath the Himalayan Arc and Tibetan Plateau: Possible Evidence for Underthrusting of Indian continental Lithosphere beneath Tibet. Geol. 10, 179-185. doi:10.1130/0091-7613(1982)10<179:vapcop >2.0.co;2

Beck, S. L., and Zandt, G. (2002). The Nature of Orogenic Crust in the central Andes. J. Geophys. Res. 107, 7-1. doi:10.1029/2000JB000124

Bird, P. (1979). Continental Delamination and the Colorado Plateau. J. Geophys. Res. 84, 7561-7571. doi:10.1029/jb084ib13p07561

Buck, W. R., and Toksöz, M. N. (1983). Thermal Effects of continental Collisions: Thickening a Variable Viscosity Lithosphere. Tectonophysics 100, 53-69. doi:10.1016/0040-1951(83)90178-6

Bürgmann, R., and Dresen, G. (2008). Rheology of the Lower Crust and Upper Mantle: Evidence from Rock Mechanics, Geodesy, and Field Observations. Annu. Rev. Earth Planet. Sci. 36, 531-567. doi:10.1146/ annurev.earth.36.031207.124326

Chen, L., Song, X., Gerya, T. V., Xu, T., and Chen, Y. (2019). Crustal Melting beneath Orogenic Plateaus: Insights from 3-D Thermo-Mechanical Modeling. Tectonophysics 761, 1-15. doi:10.1016/j.tecto.2019.03.014

Chen, M., Niu, F., Tromp, J., Lenardic, A., Lee, C.-T. A., Cao, W., et al. (2017). Lithospheric Foundering and Underthrusting Imaged beneath Tibet. Nat. Commun. 8, 15659. doi:10.1038/ncomms15659

Conrad, C. P. (2000). Convective Instability of Thickening Mantle Lithosphere. Geophys. J. Int. 143 (1), 52-70. doi:10.1046/j.1365-246x.2000.00214.x

Conrad, C. P., and Molnar, P. (1999). Convective Instability of a Boundary Layer with Temperature-And Strain-rate-dependent Viscosity in Terms of 'available Buoyancy'. Geophys. J. Int. 139, 51-68. doi:10.1046/j.1365-246x.1999.00896.x

Conrad, C. P., and Molnar, P. (1997). The Growth of Rayleigh-Taylor-type Instabilities in the Lithosphere for Various Rheological and Density

\section{ACKNOWLEDGMENTS}

I am grateful to Prof. Taras Gerya. I started working on delamination in 2013 when I visited Taras Gerya at ETH Zurich. Taras Gerya generously provided me with his stateof-the-art code, and selflessly contributed to the development of the ideas and improvement of the model setup. He was one of the best teachers I ever met. I thank Prof. An Yin and Fabio Capitanio for commenting the early draft, Xiaofeng Liang for the help during drawing the seismic tomographic images, and Zhiyong Yan for the help with drawing Figure 9. All the figures were generated with GMT (http://www.soest.hawaii.edu/ $\mathrm{gmt} /$ ).

\section{SUPPLEMENTARY MATERIAL}

The Supplementary Material for this article can be found online at: https://www.frontiersin.org/articles/10.3389/feart.2021.755519/ full\#supplementary-material

Structures. Geophys. J. Int. 129, 95-112. doi:10.1111/j.1365 246x.1997.tb00939.x

Ducea, M., and Saleeby, J. (1998). A Case for Delamination of the Deep Batholithic Crust beneath the Sierra Nevada, California. Int. Geology. Rev. 40, 78-93. doi:10.1080/00206819809465199

Elkins-Tanton, L. T. (2005). Continental Magmatism Caused by Lithospheric Delamination. Plates, Plumes and Paradigms 388, 449-461. doi:10.1130/08137-2388-4.449

Elkins-Tanton, L. T. (2007). Continental Magmatism, Volatile Recycling, and a Heterogeneous Mantle Caused by Lithospheric Gravitational Instabilities. J. Geophys. Res. 112, B03405. doi:10.1029/2005JB004072

England, P., and Houseman, G. (1986). Finite Strain Calculations of continental Deformation: 2. Comparison with the India-Asia Collision Zone. J. Geophys. Res. 91, 3664-3676. doi:10.1029/jb091ib03p03664

Gerya, T. V., Connolly, J. A. D., Yuen, D. A., Gorczyk, W., and Capel, A. M. (2006). Seismic Implications of Mantle Wedge Plumes. Phys. Earth Planet. Interiors 156, 59-74. doi:10.1016/j.pepi.2006.02.005

Gerya, T. V., Connolly, J. A. D., and Yuen, D. A. (2008). Why Is Terrestrial Subduction One-Sided? Geol. 36 (1), 43-46. doi:10.1130/g24060a.1

Gerya, T. V. (2010). Introduction to Numerical Geodynamic Modelling. London: Cambridge Univ. Press, 338.

Gerya, T. V., and Yuen, D. A. (2003). Characteristics-based Marker-In-Cell Method with Conservative Finite-Differences Schemes for Modeling Geological Flows with Strongly Variable Transport Properties. Phys. Earth Planet. Inter. 140, 295-320. doi:10.1016/j.pepi.2003.09.006

Gorczyk, W., Hobbs, B., and Gerya, T. (2012). Initiation of Rayleigh-Taylor Instabilities in Intra-cratonic Settings. Tectonophysics 514-517, 146-155. doi:10.1016/j.tecto.2011.10.016

Göğüş, O. H., and Pysklywec, R. N. (2008). Near-surface Diagnostics of Dripping or Delaminating Lithosphere. J. Geophys. Res. 113, B11404. doi:10.1029/ 2007JB005123

Guillot, S., Garzanti, E., Baratoux, D., Marquer, D., Mahéo, G., and de Sigoyer, J. (2003). Reconstructing the Total Shortening History of the NW Himalaya. Geochem. Geophys. Geosyst. 4 (7), 1064. doi:10.1029/2002GC000484

Hacker, B. R., Kelemen, P. B., and Behn, M. D. (2015). Continental Lower Crust. Annu. Rev. Earth Planet. Sci. 43, 167-205. doi:10.1146/annurev-earth-050212124117

Hansen, F. D. (1982). Semibrittle Creep of Selected Crustal Rocks at $1000 \mathrm{MPa}$. College Station, Tex.: Ph. D. Thesis, Texas A\&M University, 224.

Hirn, A., Nercessian, A., Sapin, M., Jobert, G., Xin, X. Z., Yuan, G. E., et al. (1984). Lhasa Block and Bordering Sutures- a Continuation of a 500-km Moho Traverse through Tibet. Nature 307, 25-27. doi:10.1038/307025a0 
Hirth, G., and Kohlstedt, D. (2003). "Rheology of the Upper Mantle and the Mantle Wedge: a View from the Experimentalists," in , 138, 83-105. doi:10.1029/ 138gm06Inside Subduction Factory. Geophys. Monogr. Ser.

Houseman, G. A., McKenzie, D. P., and Molnar, P. (1981). Convective Instability of a Thickened Boundary Layer and its Relevance for the thermal Evolution of continental Convergent Belts. J. Geophys. Res. 86, 6115-6132. doi:10.1029/ jb086ib07p06115

Houseman, G. A., and Molnar, P. (1997). Gravitational (Rayleigh-Taylor) Instability of a Layer with Non-linear Viscosity and Convective Thinning of continental Lithosphere. Geophys. J. Int. 128, 125-150. doi:10.1111/j.1365246x.1997.tb04075.x

Jull, M., and Kelemen, P. B. (2001). On the Conditions for Lower Crustal Convective Instability. J. Geophys. Res. 106, 6423-6446. doi:10.1029/ 2000jb900357

Kapp, P., Yin, A., Harrison, T. M., and Ding, L. (2005). Cretaceous-Tertiary Shortening, basin Development, and Volcanism in central Tibet. Geol. Soc. America Bull. 117, 865-878. doi:10.1130/b25595.1

Kay, R. W., and Mahlburg Kay, S. (1993). Delamination and Delamination Magmatism. Tectonophysics 219, 177-189. doi:10.1016/0040-1951(93) 90295-u

Kind, R., Yuan, X., Saul, J., Nelson, D., Sobolev, S. V., Mechie, J., et al. (2002). Seismic Images of Crust and Upper Mantle beneath Tibet: Evidence for Eurasian Plate Subduction. Science 298, 1219-1221. doi:10.1126/ science. 1078115

Krystopowicz, N. J., and Currie, C. A. (2013). Crustal Eclogitization and Lithosphere Delamination in Orogens. Earth Planet. Sci. Lett. 361, 195-207. doi:10.1016/j.epsl.2012.09.056

Kumar, P., Yuan, X., Kind, R., and Ni, J. (2006). Imaging the Colliding Indian and Asian Lithospheric Plates beneath Tibet. J. Geophys. Res. 111, a-n. doi:10.1029/ 2005JB003930

Lee, C.-T. A., Luffi, P., and Chin, E. J. (2011). Building and Destroying continental Mantle. Annu. Rev. Earth Planet. Sci. 39, 59-90. doi:10.1146/annurev-earth040610-133505

Lee, C.-T. A. (2014). Physics and Chemistry of Deep continental Crust Recycling, in Treatise on Geochemistry. 2nd Edn, 423-456. doi:10.1016/B978-0-08095975-7.00314-4

Li, C., van der Hilst, R. D., Meltzer, A. S., and Engdahl, E. R. (2008). Subduction of the Indian Lithosphere beneath the Tibetan Plateau and Burma. Earth Planet. Sci. Lett. 274 (1-2), 157-168. doi:10.1016/ j.epsl.2008.07.016

Mackwell, S. J., Zimmerman, M. E., and Kohlstedt, D. L. (1998). High-temperature Deformation of Dry Diabase with Application to Tectonics on Venus. J. Geophys. Res. 103, 975-984. doi:10.1029/97jb02671

McNamara, D. E., Owens, T. J., and Walter, W. R. (1995). Observations of Regional Phase Propagation across the Tibetan Plateau. J. Geophys. Res. 100 (), 22215-22229. doi:10.1029/95jb01863

McNamara, D. E., Walter, W. R., Owens, T. J., and Ammon, C. J. (1997). Upper Mantle Velocity Structure beneath the Tibetan Plateau from Pn Travel Time Tomography. J. Geophys. Res. 102, 493-505. doi:10.1029/ $96 \mathrm{jb} 02112$

Meissner, R., and Mooney, W. (1998). Weakness of the Lower continental Crust: a Condition for Delamination, Uplift, and Escape. Tectonophysics 296, 47-60. doi:10.1016/s0040-1951(98)00136-x

Moghadam, R. H., Trepmann, C. A., Stöckhert, B., and Renner, J. (2010). Rheology of Synthetic Omphacite Aggregates at High Pressure and High Temperature. J. Petrol. 51 (4), 921-945. doi:10.1093/petrology/egq006

Molnar, P., England, P., and Martinod, J. (1993). Mantle Dynamics, Uplift of the Tibetan Plateau, and the Indian Monsoon. Rev. Geophys. 31, 357-396. doi:10.1029/93rg02030

Molnar, P., Houseman, G. A., and Conrad, C. P. (1998). Rayleigh-Taylor Instability and Convective Thinning of Mechanically Thickened Lithosphere: Effects of Non-linear Viscosity Decreasing Exponentially with Depth and of Horizontal Shortening of the Layer. Geophys. J. Int. 133, 568-584. doi:10.1046/j.1365246x.1998.00510.x

Morency, C., and Doin, M.-P. (2004). Numerical Simulations of the Mantle Lithosphere Delamination. J. Geophys. Res. 109, B03410. doi:10.1029/ 2003jb002414
Murphy, M. A., Yin, A., Harrison, T. M., Dürr, S. B., Z, C., Ryerson, F. J., et al. (1997). Did the Indo-Asian Collision Alone Create the Tibetan Plateau? Geol. 25 (8), 719-722. doi:10.1130/0091-7613(1997)025<0719: dtiaca>2.3.co;2

Negredo, A. M., Replumaz, A., Villaseñor, A., and Guillot, S. (2007). Modeling the Evolution of continental Subduction Processes in the Pamir-Hindu Kush Region. Earth Planet. Sci. Lett. 259, 212-225. doi:10.1016/ j.epsl.2007.04.043

Owens, T. J., and Zandt, G. (1997). Implications of Crustal Property Variations for Models of Tibetan Plateau Evolution. Nature 387 (6628), 37-43. doi:10.1038/ $387037 \mathrm{a} 0$

Pinkerton, H., and Stevenson, R. J. (1992). Methods of Determining the Rheological Properties of Magmas at Sub-liquidus Temperatures. J. Volcanology Geothermal Res. 53, 47-66. doi:10.1016/0377-0273(92) 90073-m

Priestley, K., Debayle, E., McKenzie, D., and Pilidou, S. (2006). Upper Mantle Structure of Eastern Asia from Multimode Surface Waveform Tomography. J. Geophys. Res. 111, B10304. doi:10.1029/2005JB004082

Pysklywec, R. N., and Beaumont, C. (2004). Intraplate Tectonics: Feedback between Radioactive thermal Weakening and Crustal Deformation Driven by Mantle Lithosphere Instabilities. Earth Planet. Sci. Lett. 221, 275-292. doi:10.1016/s0012-821x(04)00098-6

Ranalli, G. (1995). Rheology of the Earth: Deformation and Flow Processes in Geophysics and Geodynamics. 2nd ed. London: Chapman \& Hall.

Replumaz, A., and Tapponnier, P. (2003). Reconstruction of the Deformed Collision Zone between India and Asia by Backward Motion of Lithospheric Blocks. J. Geophys. Res. 108 (B6), 2285. doi:10.1029/ 2001JB000661

Rybacki, E., and Dresen, G. (2000). Dislocation and Diffusion Creep of Synthetic Anorthite Aggregates. J. Geophys. Res. 105 (B11), 26017-26036. doi:10.1029/ 2000jb900223

Schaeffer, A. J., and Lebedev, S. (2013). Global Shear Speed Structure of the Upper Mantle and Transition Zone. Geophys. J. Int. 194 (1), 417-449. doi:10.1093/gii/ ggt095

Schott, B., and Schmeling, H. (1998). Delamination and Detachment of a Lithospheric Root. Tectonophysics 296, 225-247. doi:10.1016/s0040-1951(98) 00154-1

Schurr, B., Rietbrock, A., Asch, G., Kind, R., and Oncken, O. (2006). Evidence for Lithospheric Detachment in the central Andes from Local Earthquake Tomography. Tectonophysics 415, 203-223. doi:10.1016/j.tecto.2005.12.007

Tilmann, F., and Ni, J. (2003). INDEPTH Seismic teamSeismic Imaging of the Downwelling Indian Lithosphere beneath central Tibet. Science 300, 1424-1427. doi:10.1126/science.1082777

Wang, C., Zhao, X., Liu, Z., Lippert, P. C., Graham, S. A., Coe, R. S., et al. (2008). Constraints on the Early Uplift History of the Tibetan Plateau. Pnas 105 (13), 4987-4992. doi:10.1073/pnas.0703595105

Wang, Y. F., Zhang, J. F., Jin, Z. M., and Green, H. W. (2012). Green II, H.W.,Mafic Granulite Rheology: Implications for a Weak continental Lower Crust. Earth Planet. Sci. Lett. 353-354, 99-107. doi:10.1016/ j.epsl.2012.08.004

Wei, W. (2001). Detection of Widespread Fluids in the Tibetan Crust by Magnetotelluric Studies. Science 292, 716-719. doi:10.1126/ science. 1010580

Wen, D. P., Wang, Y. F., Zhang, J. F., Li, P. X., and Jin, Z. M. (2021). Rheology of Felsic Granulite at High Temperature and High Pressure. J. Geophys. Res. Solid Earth 126, e2020JB020966. doi:10.1029/2020JB020966

Wilks, K. R., and Carter, N. L. (1990). Rheology of Some continental Lower Crustal Rocks. Tectonophysics 182, 57-77. doi:10.1016/0040-1951(90) 90342-6

Yin, A. (2010). Cenozoic Tectonic Evolution of Asia: A Preliminary Synthesis. Tectonophysics 488, 293-325. doi:10.1016/j.tecto.2009.06.002

Yuan, X., Sobolev, S. V., Kind, R., Oncken, O., Bock, G., Asch, G., et al (2000). Subduction and Collision Processes in the Central Andes Constrained by Converted Seismic Phases. Nature 408, 958-961. doi: $10.1038 / 35050073$

Zhang, J., Greenii, H., II, and Bozhilov, K. (2006). Rheology of Omphacite at High Temperature and Pressure and Significance of its Lattice Preferred 
Orientations. Earth Planet. Sci. Lett. 246, 432-443, doi:10.1016/ j.epsl.2006.04.006

Zhao, W., Kumar, P., Mechie, J., Kind, R., Meissner, R., Wu, Z., et al. (2011). Tibetan Plate Overriding the Asian Plate in central and Northern Tibet. Nat. Geosci. 4 (12), 870-873. doi:10.1038/ngeo1309

Zhou, Y., Rybacki, E., Wirth, R., He, C., and Dresen, G. (2012). Creep of Partially Molten fine-grained Gabbro under Dry Conditions. J. Geophys. Res. 117, B05204. doi:10.1029/2011JB008646

Conflict of Interest: The author declares that the research was conducted in the absence of any commercial or financial relationships that could be construed as a potential conflict of interest.
Publisher's Note: All claims expressed in this article are solely those of the authors and do not necessarily represent those of their affiliated organizations, or those of the publisher, the editors and the reviewers. Any product that may be evaluated in this article, or claim that may be made by its manufacturer, is not guaranteed or endorsed by the publisher.

Copyright $\odot 2021$ Chen. This is an open-access article distributed under the terms of the Creative Commons Attribution License (CC BY). The use, distribution or reproduction in other forums is permitted, provided the original author(s) and the copyright owner(s) are credited and that the original publication in this journal is cited, in accordance with accepted academic practice. No use, distribution or reproduction is permitted which does not comply with these terms. 